Research Article

\section{Lateral Pancreato-Jejunostomy in Chronic Pancreatitis: An appraisal of} 32 cases

\author{
Sardar Rezaul Islam ${ }^{1 *}$, Shafiqur Rahman², Shaurav Talukdar ${ }^{3}$, \\ Shah Alam Sarkar ${ }^{4}$, Shah Poran ${ }^{5}$ and Mushfiqur Rahman ${ }^{5}$
}

1Professor and Head, Department of Surgery, Imperial Hospital, (IHL) Chattogram, Bangladesh ${ }^{2}$ Professor and Head, Department of Radiology and Imaging, Jahurul Islam Medical College Hospital (JIMCH), Bajitpur, Kishoreganj, Bangladesh

${ }^{3}$ Assittant Professor, Anesthesia and Critical Care Medicine, JIMCH, Bangladesh

${ }^{4}$ Registrar, Department of Surgery, IHL, Bangladesh

${ }^{5}$ Registrar, Department of Surgery, JIMCH, Bangladesh

\section{Abstract}

Background: Lateral Pancreaticojejunostomy (LPJ) has recognized applications in the management of Chronic Pancreatitis (CP). It is done for patients with severe pain, obstructed and dilated pancreatic duct. Ductal obstruction by stone or stricture causes rise of intraductal pressure and parenchymal ischemia. Surgical decompression of the duct and ductal drainage can achieve best pain relieve and slow the progression of the disease. We want to share our experience of removal of stones and strictures from the pancreatic duct system and drainage of the main pancreatic duct by lateral pancreatojejunostomy (LPJ) for chronic pancreatitis in a teaching institute.

Methodology: We studied 32 cases of chronic pancreatitis operated between January 2010 and January 2017 for a period of 7 years. Patients were selected with ultrasonography, CT scan and or Magnetic Resonance Cholangio Pancreatography (MRCP). Dilatation of the main pancreatic duct by at least $7 \mathrm{~mm}$ proximal to the obstruction were recruited for operation. We did Roux-Y lateral pancreato-jejunostomy for patients with obstruction of the pancreatic duct due to intraductal stones or strictures. Additional distal pancreatectomy were done in two cases for stones and/or abscess in the tail area. We did one Frey's operation for stone and fibro-calcification of the head. In all cases ductal drainage was accomplished by LPJ. We studied their post-operative pain control, complications, recurrence and improvement of exocrine and endocrine function of pancreas and mortality during this period. We followed these patients for about 2 years after surgery.

Results: We found 27 out of 32 patients got complete remission of the abdominal pain. Their progression of disease also slowed down. Ultrasonic evidence of chronic pancreatitis have improved or resolved. Ductal diameter have decreased. Two had recurrence of stones in the head and in the parenchyma within a year. 2 patients died during this follow-up period. One died three months after LPJ due to massive gangrene of the small intestine distal to LPJ and jejunojejunostomy and subsequent short bowel syndrome. Other one died of complications of diabetes and malabsorbtion. Pain free survival is about $84 \%$ and recurrence is $6 \%$. Mortality during this follow up period is $6 \%$.

Conclusion: We found that surgery, if done early, can have good remission of abdominal pain and can slow the progression of chronic pancreatitis and prevent further stone formation in majority of patients. Patient's exocrine and endocrine function improves or remain static. Patient with chronic calcific pancreatitis and diabetes are unlikely to have favorable outcome even after decompressive surgery.

\section{More Information \\ *Address for Correspondence: Sardar Rezaul Islam, Professor and Head, Department of Surgery, Imperial Hospital, (IHL) Chattogram, Bangladesh, Tel: +8801746603305; \\ 01633325514; Email: islamreza@hotmail.com; islamreza91@gmail.com}

Submitted: 13 January 2020

Approved: 27 January 2020

Published: 28 January 2020

How to cite this article: Islam SR, Rahman S, Talukdar S, Sarkar SA, Poran S, et al. Lateral Pancreato-Jejunostomy in Chronic Pancreatitis: An appraisal of 32 cases. Arch Surg Clin Res. 2020; 4: 001-005.

DOI: dx.doi.org/10.29328/journal.ascr.1001043 ORCiD: orcid.org/0000-0003-1685-1208

Copyright: (c) 2020 Islam SR, et al. This is an open access article distributed under the Creative Commons Attribution License, which permits unrestricted use, distribution, and reproduction in any medium, provided the original work is properly cited.

Keywords: Chronic pancreatitis; Pancreatic duct stone; Lateral pancreatojejunostomy

(W) Check for updates

OPEN ACCESS

\section{Introduction}

Chronic pancreatitis is a progressive inflammatory disease of varied etiology characterized by stone formation, destruction of pancreatic parenchyma and subsequent fibrosis [1]. There is an increased incidence in recent years. Its pathogenesis remains unknown. Alcohol is a major etiological factor in most industrialized countries [2]. Pancreatic duct calcifications are common in patients with chronic pancreatitis, and up to $90 \%$ of patients with alcoholic 
chronic pancreatitis have such stones during long-term follow-up [3]. Pancreatic duct calculi can lead to an outflow obstruction of the pancreatic duct, resulting in upstream hypertension, increased parenchymal pressure, and ischemia. Pain is the predominant symptom in most patients with chronic pancreatitis [4]. The etiology of pain is multifactorial, although ductal hypertension caused by stones or strictures is believed to be the major cause of pain in patients with chronic pancreatitis [4-9]. Removal of pancreatic duct stones decreases the pain. Additionally, restitution of pancreatic duct flow improves physiological function of the pancreas [10-12].

A pancreatic duct obstruction due to main pancreatic duct stones can often be relieved by surgical or endoscopic techniques or extracorporeal shock wave lithotripsy (ESWL). Removing pancreatic stones endoscopically is less invasive compared to surgery but is more likely to be successful when the stone burden is small and located only in the main duct [13-15]. ERCP based extraction is a critical treatment for pancreatic duct stone. There is high incidence of postprocedure acute pancreatitis [8-10]. Moreover endoscopic removal has limitation in dealing with huge load of impacted stone and pancreatic duct stricture. Endoscopic extraction is also not able to achieve adequate drainage of the duct in a situation of multiple duct stricture. Pancreatic cancer may further complicate long standing disease, which should be treated by pancreatic resection.

Different surgical procedures can be chosen according to the location of the stones in the pancreatic duct. If the stones are mainly located in the body of the pancreas, they can be treated with Puestow-Gillesby procedure (pancreatojejunostomy), which is often used in patients with significant dilation of the pancreatic duct. Though Puestow-Gillesby first described this operation, but Parrington-Rochelle modified this operation and performed long length LPJ. This operation is still known as Puestow operation. Resection of the tail of the pancreas with or without splenectomy is done if the stones are located in the tail of the pancreas. Sometimes the stones are found in the head of the main duct of the pancreas. In that case excision of the head is done with preservation of the duodenum and CBD. This is called Berger's procedure. Excision of the duct of Wirsung and Santorini in the head with long length LPJ is called Frey's operation. Some extreme cases require pancreato-duodenectomy (Whipple's procedure).

\section{Pathophysiology}

Pancreatic juice is supersaturated with calcium. Calcium is kept in solution by $\mathrm{HCO}_{3}$, citrate, and pancreatic stone protein (PSP), and these factors are lower in patients with chronic pancreatitis [16]. Alcohol, protein malnutrition and chronic pancreatitis decrease the secretion of PSP, which causes the crystallization and deposition of calcium carbonate and the formation of stones [17] This is the reason why chronic pancreatitis is more prevalent in rural part of India and Bangladesh in low socioeconomic background. Genetic mutations such as SPINK1 gene mutation may responsible for development of chronic pancreatitis. Pancreatic duct strictures cause stagnation of pancreatic juice and enhance the formation of pancreatic stones. Hypercalcemia may cause a rise in the level of calcium in pancreatic juice, which accelerates the formation of pancreatic stones in patients with hyperparathyroidism. Calcium precipitates as $\mathrm{CaCO}_{3}$. These stones are radio-opaque and readily visible on plain $\mathrm{x}$-ray unlike gall stone.

\section{Methodology}

\section{Patients}

Any patient diagnosed by Ultrasonography with dilated MPD with or without pancreatic duct stone were recruited for the study (Figure 1). They were further evaluated with CBC, Creatinine, Liver function test, Serum calcium, Plain $\mathrm{X}$-ray abdomen, CT scan, Magnetic Resonance Cholangio Pancreatography (MRCP). MPD diameter more than $7 \mathrm{~mm}$ were selected for surgery. Age of patient ranges from 11 to 60 years with median age of 31 years. Male: female ratio was $2: 3$. Most of the patient were operated in the same admission. Any evidence of acute infection on top of chronic pancreatitis were given antibiotic treatment and the surgery done following week.

\section{Surgery}

All patients were operated with upper midline incision under general anesthesia. Patient with stone in the body and head area had LPJ alone in Roux-Y manner (Figure 6). Patient with stone in the tail area had additional distal pancreatectomy (Figures 1-3) the main pancreatic ducts were opened until all stones removed and strictures opened up (Figure 5). The length of pancreato-docotomy ranged between 6 to $10 \mathrm{~cm}$ depending upon number of stones and strictures. Roux-Y limb of the jejunum was anastomosed with the pancreas with $2 / 0$ vicryl interrupted or continuous in single layer (Figures 6,7) Roux-Y jejuno-jejunal anastomosis is done $60 \mathrm{~cm}$ down the LPJ. We did one Frey's procedure for fibrocalcification of head of the pancreas and dilated CBD. Concomitant CBD obstruction had additional choledocojejunostomy. All patients were discharged on complete remission of post-operative pain and resumption of normal diet.

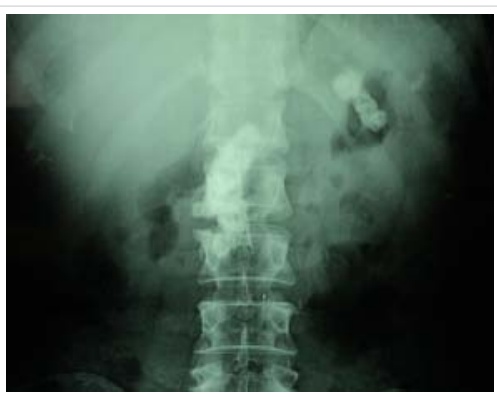

Figure 1: Plain X-ray showing a large pancreatic duct stone. 


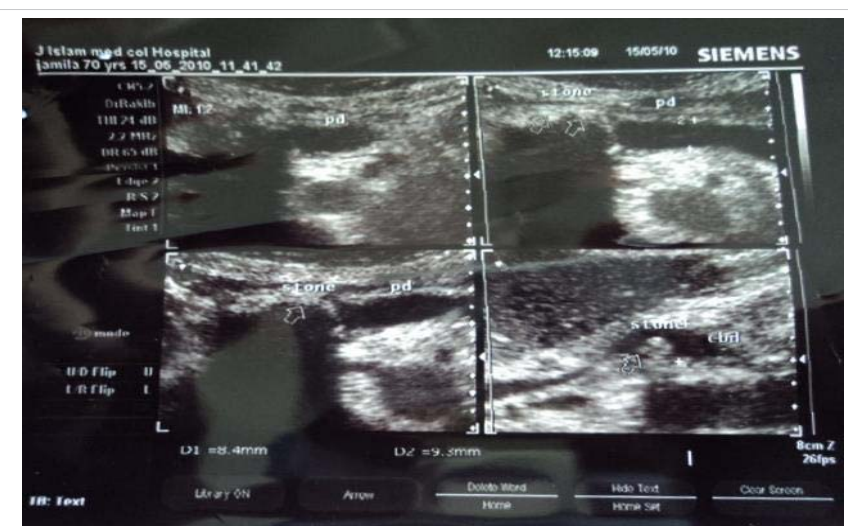

Figure 2: USG showing stone in MPD and CBD.

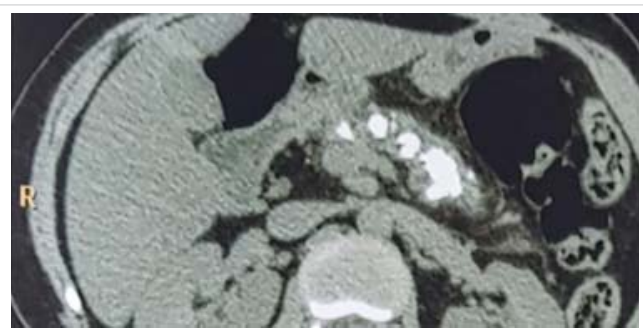

Figure 3: Limited CT scan, Stone seen in the head, body and tail of the pancreas (This patient required distal pancreatectomy)

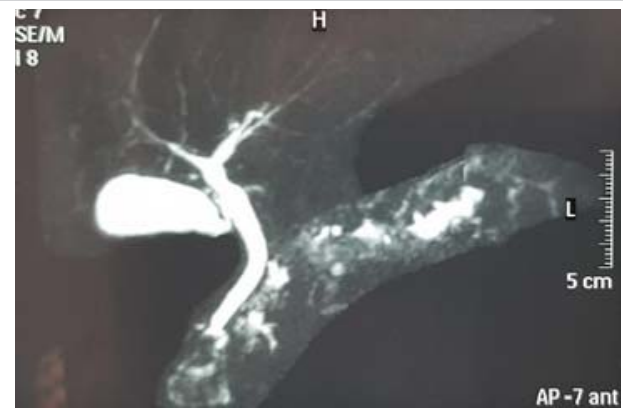

Figure 4: MRCP, Stone seen in the head, body and tail of the pancreas (This patient required distal pancreatectomy).

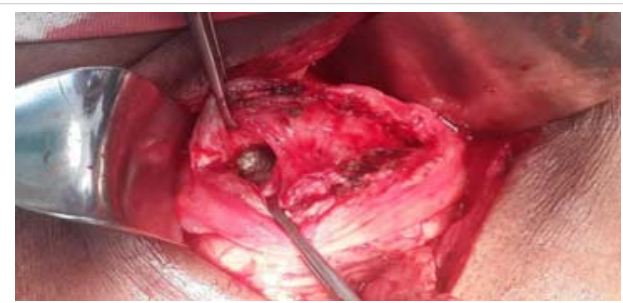

Figure 5: Stone is seen on pancreato-docotomy.

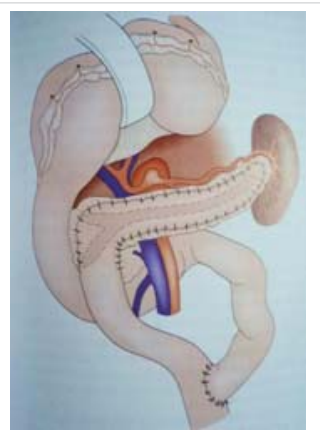

Figure 6: Roux Y LPJ.

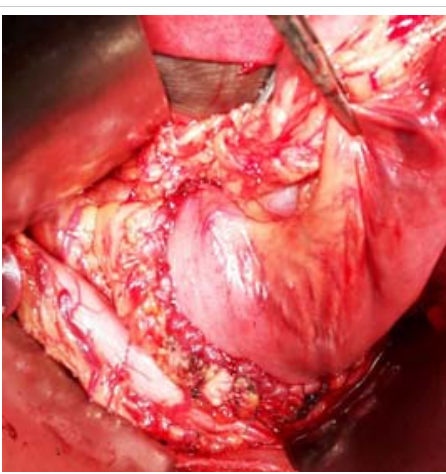

Figure 7: Anastomosis between the pancreas and Jejunum.

\begin{tabular}{|c|c|c|}
\hline \multicolumn{2}{|c|}{ Table 1: Summery of the operative findings and hospital stay. } \\
\hline & Mean & Range \\
\hline MPD diameter & $13.7 \mathrm{~mm}$ & 7 to $26 \mathrm{~mm}$ \\
\hline Duration of operation & $1.45 \mathrm{~min}$ & 1.25 to $2.35 \mathrm{~min}$ \\
\hline Post-op hospital stay & 8.5 days & $7-13$ days \\
\hline
\end{tabular}

Table 2: Pathology, procedure done and outcome.

\begin{tabular}{|c|c|c|c|}
\hline $\begin{array}{l}\text { No of } \\
\text { cases }\end{array}$ & Per-operative findings & Procedure done & Outcome \\
\hline 28 & $\begin{array}{c}\text { Stone in the body and } \\
\text { or Head }\end{array}$ & LPJ & $\begin{array}{l}25 \text { are alive } \\
1 \text { died } \\
1 \text { recurrence in the head (MPD) } \\
1 \text { recurrence in the parenchyma }\end{array}$ \\
\hline 1 & $\begin{array}{c}\text { Fibro calcification and } \\
\text { stone in the head of the } \\
\text { pancreas }\end{array}$ & $\begin{array}{c}\text { Frey's operation } \\
\text { and LPJ }\end{array}$ & Alive \\
\hline 2 & $\begin{array}{l}\text { Stone in the head, body } \\
\text { and tail }\end{array}$ & $\begin{array}{c}\text { Distal } \\
\text { pancreatectomy } \\
\text { and LPJ }\end{array}$ & Alive \\
\hline 1 & $\begin{array}{c}\text { MPD stone and } \\
\text { obstructed CBD due to } \\
\text { peri-ampullary stricture. }\end{array}$ & $\begin{array}{c}\text { Choledocho- } \\
\text { jejunostomy and } \\
\text { LPJ }\end{array}$ & $\begin{array}{c}\text { Died about one year after } \\
\text { surgery due to complications of } \\
\text { diabetes. }\end{array}$ \\
\hline
\end{tabular}

\section{Follow up}

Patients were scheduled to be seen one week after discharge and 6 weeks and 6 months and 2 year after surgery. They were evaluated for abdominal pain, malabsorption and diabetes. USG of the abdomen and plain X-ray were done to see the condition of the pancreas and recurrence of stone.

\section{Follow up treatment}

Tramadol or paracetamol were given as analgesic. Pancreatic supplement enzyme was given only if patient complaints of steatorrhea or persistent loose stool. Insulin therapy was continued in diabetic patient.

\section{Results}

The average diameter of the main pancreatic duct (MPD) was $13.7 \mathrm{~mm}$ and ranges from 7 to $26 \mathrm{~mm}$. The mean operation time for pancreato-jejunostomy alone was one hour and 45 minutes ranging from 1 hour $25 \mathrm{~min}$ to 2 hour 35 min. Median post operative hospital stay was 8.5 days ranging from 7 to 13 days. There were no death within 30 days of surgery in our series.

There were one case of recurrence in the head area 
another in the parenchyma within one year of LPJ. 2 patients died during 2 years follow up period. One patient developed intestinal obstruction within 3 weeks of surgery. He was re-operated and found to have gangrene of small intestine distal to the LPJ anastomotic site. He had undergone massive resection of jejunum and ileum. He died of short bowel syndrome within two months of the second surgery. $2^{\text {nd }}$ patient died of complications of diabetes and malabsorbtion. 27 patients are free from pain and do not need any analgesics. Rate of pain free survival in our series in a 2 year follow up is $84 \%$. And mortality is $6 \%$. Recurrence of stone is $6 \%$.

\section{Discussion}

Diagnoses and evaluations of chronic calcific pancreatitis are evaluated by history and clinical examination, plain x-ray abdomen, ultrasonography, computed tomography (CT), endoscopic retrograde cholangio-pancreatography (ERCP) and Magnetic Resonance Cholangio-pancreatography (MRCP). In my experience utrasonography is very helpful. It gives the diameter of the MPD and distance of the duct from the anterior surface of the pancreas, which are helpful information for surgery. I operated many of these patients just on the basis of untrasonographic findings only. MRCP can precisely reveal pancreatic duct stones, pancreatitis, pancreatic tumor, and pancreatic cyst. Contrast enhanced CT scan is also needed to exclude pancreatic neoplasm. Pancreatic tumor marker like CA19-9 also should be done to exclude malignancy. But it is often raised in chronic pancreatitis also. Frozen section biopsy during surgery is possibly the best way to exclude malignanacy. Two of my patients developed pancreatic cancer within short period after LPJ. Per-operative frozen were not done due unavailability. They were excluded from the study as they were harboring malignancy at the time of LPJ.

Different surgical procedures can be chosen according to the location of the stones in the pancreatic duct [7]. When the stones are mainly located in the head of pancreas and stone size is less than $5 \mathrm{~mm}$, endoscopic drainage and removal of the stones is usually the first choice of treatment. Larger stones can be broken down by ESWL. If it fails, surgical procedure should be applied. If the stones are mainly located in the body of the pancreas, they can be treated with PuestowGillesby procedure or Lateral pancreato-jejunostomy (LPJ), which is often used in patients with significant dilation of the pancreatic duct. Resection of the tail of the pancreas or combined resection with or without splenectomy is done if the stones are located in the tail of the pancreas. Sometimes the stones are found in the head of the pancreas. In that case local excision of the head and lateral pancreatojejunostomy (LR-LPJ) becomes the choice of treatment. This is called Frey's operation.

We performed the Parrington-Rochelle modification of LPJ in all cases. One of our case had additional spleen preserving distal pancreatectomy for presence of stone in the tail area.
Another 35 year old woman presented with extensive ductal stone and abscess in the tail area. Distal pancreatectomy, spenectomy and LPJ done for her. She recovered fully. She needs insulin for her diabetes. We did Frey's operation for one patient. This patient had stone and severe fibro-calcification of the head.

We performed simultaneous choledco-jejunostomy in one patient for concomitant CBD obstruction due to severe fibrocalcific stricture at the lower end of the CBD. This patient came with severe jaundice. Serum bilirubin was about 16 $\mathrm{mg} / \mathrm{dl}$. CBD and pancreatic duct were anastomosed with the $Y$ limb of the jejunum in a series manner. His Jaundice was completely cleared in two weeks time.

The first mortality was due to massive intestinal resection and short bowel syndrome. This patient had a biliary stent and pancreatic duct stent, which were inserted 3 months before the surgery in an Abu Dhabi hospital. These stents were all removed during LPJ. He developed acute intestinal obstruction within 3 weeks after surgery. Re-laparotomy was done and massive gangrene of the small bowel distal to the pancreatojejunostomy was seen and resection done. Later he developed short bowel syndrome and died 3 months after the second surgery. As none of our patients developed this type of complication in postoperative period, we think that pancreatic stent related infection or toxicity was responsible for this massive gangrene of the intestine. So we recommend that all stents should be removed sometime before the surgery endoscopically and should be treated with antibiotic. Moreover this patient was severely diabetic. He had severe degree of chronic pancreatitis and malabsorption, requiring pancreatic supplement prior to operation. The second mortality was due multiple complications arising from diabetes and malabsorbtion.

Management of pancreatic duct stones continue to evolve, and it is dependent on the available facilities [19]. Treatments including surgical, endoscopic techniques, laser lithotripsy, extracorporeal shock wave lithotripsy (ESWL), balloon stenting, and medications are effective. The success of endoscopic intervention, as a less invasive procedure in the treatment of pancreatic stones, is partly due to the improvement of endoscopic techniques. However, pancreatic duct stones approximately $5 \mathrm{~mm}$ or greater are often not amenable to conventional management with sphincterotomy, stricture dilation, or stone retrieval with basket [20]. In this setting, ESWL has been found to be a very successful modality which historically had been used exclusively in the treatment of renal stones, with an ability to fragment large stones [21].

In one study endoscopic therapy and surgical drainage was compared. They found that complete or partial pain relief was achieved at the end of follow-up in $32 \%$ of patients in the endoscopy group and $75 \%$ of patients in the surgery group ( $p=0.007$ ) [22]. Patients who undergo surgery as 
their initial treatment for chronic pancreatitis require less consecutive interventions, a shorter hospital stay, and have a better quality of life compared with any other treatment [23].

Compared to the endoscopic approach, surgical risks are often the major concern in surgical intervention for pancreatic stones, which may be associated with operative morbidity and mortality. Fortunately, unacceptable procedure-related risk of surgical intervention seems to be not higher than that of endoscopic techniques, laser lithotripsy, and ESWL [24].

\section{Conclusion}

Successful removal of pancreatic duct stones and drainage of the pancreatic duct can reduce pain and improve pancreatic function in majority of patients. Roux Y lateral pancreatojejunostomy is the best way to achieve that drainage. Patients with chronic calcific pancreatitis and diabetes are unlikely to have favorable outcome even after de-compressive surgery.

\section{References}

1. Teemed B, Whitcomb DC. Chronic pancreatitis: diagnosis, classification, and new genetic developments. Gastroenterology. 2001; 120: 682-707.

2. Feldman $M$, Friedman LS, Brandt LJ. Slazenger and FORTRAN's gastrointestinal and liver disease. 9th ed. Philadelphia, PA: Saunders Elsevier. 2010. 203-237.

3. Amman RW, Munch R, Otto R, Buehler H, Freiburghaus AU, et al. Evolution and regression of pancreatic calcification in chronic pancreatitis: a prospective long-term study of 107 patients. Gastroenterology. 1988; 95: 1018-1028.

PubMed: https://www.ncbi.nlm.nih.gov/pubmed/3410215

4. Steer ML, Waxman I, Freedman S. Chronic pancreatitis. N Engle J Med. 1995; 332: 1482-1490.

PubMed: https://www.ncbi.nlm.nih.gov/pubmed/7739686

5. Mitchell RM, Byrne MF, Baillie J. Pancreatitis. Lancet. 2003; 361: 1447-1455.

PubMed: https://www.ncbi.nlm.nih.gov/pubmed/12727412

6. O'Hara H, Hoshino M, Hayakawa T, Kamiya Y, Miyaji M, et al. Single application extracorporeal shock wave lithotripsy is the first choice for patients with pancreatic duct stones. Am J Gastroenterology. 1996; 91: 1388-1394.

PubMed: https://www.ncbi.nlm.nih.gov/pubmed/8678001

7. Ebbehoj N, Burly L, Bulow J, Rasmussen SG, Madsen P. Evaluation of pancreatic tissue fluid pressure and pain in chronic pancreatitis: a longitudinal study. Scand J Gastroenterology. 1990; 25: 462-466. PubMed: https://www.ncbi.nlm.nih.gov/pubmed/2359973

8. Kazanjian ND, Rebar HA. The cause and management of the pain of chronic pancreatitis. Gastroenterol Clin North Am. 1990; 19: 895904.

PubMed: https://www.ncbi.nlm.nih.gov/pubmed/2269524

9. Koppel G. Pathology of chronic pancreatitis and pancreatic pain. Acta Chir Scand. 1990; 156: 261-265.

PubMed: https://www.ncbi.nlm.nih.gov/pubmed/2349844
10. Nealon WH, Townsend CM Jr, Thompson JC. Operative drainage of the pancreatic duct delays functional impairment in patients with chronic pancreatitis: a prospective analysis. Ann Surg. 1988; 208: 321-329.

PubMed: https://www.ncbi.nlm.nih.gov/pubmed/3421756

11. Greenlee HB, Print RA, Arana GV. Long-term results of side-to-side pancreaticojejunostomy. World J Surg. 1990; 14: 70-76. PubMed: https://www.ncbi.nlm.nih.gov/pubmed/2407040

12. Adler DG, Lichtenstein D, Baron TH, Davila R, Egan JV, et al. The role of endoscopy in patients with chronic pancreatitis. Gastrointest Endosc. 2006; 63: 933-937.

PubMed: https://www.ncbi.nlm.nih.gov/pubmed/16733106

13. Sherman S, Lehman GA, Hawes RH, Ponich T, Miller LS, et al. Pancreatic ductal stones: frequency of successful endoscopic removal and improvement in symptoms. Gastrointest Endosc. 1991; 37: 511-517. PubMed: https://www.ncbi.nlm.nih.gov/pubmed/1936826

14. Adamek HE, Jakobs R, Buttmann A, Adamek MU, Schneider AR, et al. Long term follow up of patients with chronic pancreatitis and pancreatic stones treated with extracorporeal shock wave lithotripsy. Gut. 1999; 45: 402-405.

PubMed: https://www.ncbi.nlm.nih.gov/pubmed/10446109

15. Delhaye $M$, Arvanitakis $M$, Verset $G$, Cremer $M$, Deviere J. Long-term clinical outcome after endoscopic pancreatic ductal drainage for patients with painful chronic pancreatitis. Clin Gastroenterol Hepatol. 2004; 2: 1096-1106.

PubMed: https://www.ncbi.nlm.nih.gov/pubmed/15625655

16. Rao KN, Van Thiel DH. Pancreatic stone protein: what is it and what does it do? Dig Dis Sci.1991; 36: 1505-1508.

PubMed: https://www.ncbi.nlm.nih.gov/pubmed/19160596

17. Tanaka T, Miura Y, Ichiba Y, Itoh H, Dohi K. Experimental pancreatolithiasis: association with chronic alcoholic pancreatitis. Am J Gastroenterol. 1992; 87: 1061-1071. PubMed: https://www.ncbi.nlm.nih.gov/pubmed/1642213

18. Reddy DN, Surinam PV Das G, Rao GV. Endoscopic treatment of pancreatic disorder. Tropical Gastroenterol. 2001; 22: 149-154.

19. Deviere J, Delhaye M, Cremer M. Pancreatic duct stones management. Gastrointestinal Endows Clin N Am. 1998; 8: 163-179.

20. Lehman GA. Role of ERCP and other endoscopic modalities in chronic pancreatitis. Gastrointest Endosc. 2002; 56: 237-240. PubMed: https://www.ncbi.nlm.nih.gov/pubmed/12447274

21. Guda NM, Freeman ML, Smith C. Role of extracorporeal shock wave lithotripsy in the treatment of pancreatic stones. Rev Gastroenterol Disord. 2005; 5: 73-81.

PubMed: https://www.ncbi.nlm.nih.gov/pubmed/15976738

22. Cahen DL, Gouma DJ, Nio Y, Rauws EA, Boermeester MA, et al. Endoscopic vs Surgical drainage of pancreatic duct in Chronic pancreatitis. N Engl J Med. 2007; 356: 676-684.

PubMed: https://www.ncbi.nlm.nih.gov/pubmed/17301298

23. Rutter K, Ferlitsch A, Sautner T, Püspök A, Götzinger $P$, et al. Hospitalization, frequency of interventions, and quality of life after endoscopic, surgical, or conservative treatment in patients with chronic pancreatitis. World J Surg. 2010; 34: 2642-2647. PubMed: https://www.ncbi.nlm.nih.gov/pubmed/20645098

24. Fang $\mathrm{WL}$, Shyr $\mathrm{YM}$, Su $\mathrm{CH}$, Chen $\mathrm{TH}$, Wu CW, et al. Long-term follow-up study of surgical treatment for pancreatic stones. Hepatogastroenterology. 2007; 54: 246-249. PubMed: https://www.ncbi.nlm.nih.gov/pubmed/17419270 